\title{
Right ventricular failure in patients with the HeartMate II continuous-flow left ventricular assist device: Incidence, risk factors, and effect on outcomes
}

\author{
Robert L. Kormos, MD, ${ }^{\mathrm{a}}$ Jeffrey J. Teuteberg, MD, ${ }^{\mathrm{b}}$ Francis D. Pagani, MD, ${ }^{\mathrm{c}}$ Stuart D. Russell, MD, ${ }^{\mathrm{d}}$ \\ Ranjit John, MD, ${ }^{\mathrm{e}}$ Leslie W. Miller, MD, ${ }^{\mathrm{f}}$ Todd Massey, MD, ${ }^{\mathrm{g}}$ Carmelo A. Milano, MD, ${ }^{\mathrm{h}}$ \\ Nader Moazami, MD, ${ }^{i}$ Kartik S. Sundareswaran, $\mathrm{PhD},{ }^{\mathrm{j}}$ and David J. Farrar, $\mathrm{PhD},{ }^{\mathrm{j}}$ \\ for the HeartMate II Clinical Investigators
}

\begin{abstract}
Objective: The aim of this study was to evaluate the incidence, risk factors, and effect on outcomes of right ventricular failure in a large population of patients implanted with continuous-flow left ventricular assist devices.

Methods: Patients $(n=484)$ enrolled in the HeartMate II left ventricular assist device (Thoratec, Pleasanton, Calif) bridge-to-transplantation clinical trial were examined for the occurrence of right ventricular failure. Right ventricular failure was defined as requiring a right ventricular assist device, 14 or more days of inotropic support after implantation, and/or inotropic support starting more than 14 days after implantation. Demographics, along with clinical, laboratory, and hemodynamic data, were compared between patients with and without right ventricular failure, and risk factors were identified.
\end{abstract}

Results: Overall, $30(6 \%)$ patients receiving left ventricular assist devices required a right ventricular assist device, $35(7 \%)$ required extended inotropes, and $33(7 \%)$ required late inotropes. A significantly greater percentage of patients without right ventricular failure survived to transplantation, recovery, or ongoing device support at 180 days compared with patients with right ventricular failure $(89 \%$ vs $71 \%, P<.001)$. Multivariate analysis revealed that a central venous pressure/pulmonary capillary wedge pressure ratio of greater than 0.63 (odds ratio, $2.3 ; 95 \%$ confidence interval, $1.2-4.3 ; P=.009$ ), need for preoperative ventilator support (odds ratio, 5.5; 95\% confidence interval, 2.3-13.2; $P<.001$ ), and blood urea nitrogen level of greater than $39 \mathrm{mg} / \mathrm{dL}$ (odds ratio, 2.1; $95 \%$ confidence interval, $1.1-4.1 ; P=.02$ ) were independent predictors of right ventricular failure after left ventricular assist device implantation.

Conclusions: The incidence of right ventricular failure in patients with a HeartMate II ventricular assist device is comparable or less than that of patients with pulsatile-flow devices. Its occurrence is associated with worse outcomes than seen in patients without right ventricular failure. Patients at risk for right ventricular failure might benefit from preoperative optimization of right heart function or planned biventricular support. (J Thorac Cardiovasc Surg 2010;139:1316-24)

An estimated 200,000 Americans over the age of 45 years have advanced heart failure for which medical therapy is

\footnotetext{
From the Heart, Lung \& Esophageal Institute ${ }^{\mathrm{a}}$ and Cardiovascular Institute, ${ }^{\mathrm{b}}$ University of Pittsburgh Medical Center, Pittsburgh, Pa; the Section of Cardiac Surgery, University of Michigan, Ann Arbor, Mich; Department of Medicine, ${ }^{\mathrm{d}}$ Johns Hopkins Hospital, Baltimore, Md; the Division of Cardiothoracic Surgery, University of Minnesota, Minneapolis, Minn; Department of Cardiovascular Medicine, ${ }^{\mathrm{f}}$ Washington Hospital Center, Washington, DC; Division of Cardiac Surgery, ${ }^{\mathrm{g}}$ University of Rochester, Rochester, NY; Division of Cardiovascular and Thoracic Surgery, ${ }^{\text {h }}$ Duke University Medical Center, Durham, NC; Division of Cardiothoracic Surgery, ${ }^{\mathrm{i}}$ Washington University School of Medicine, St Louis, Mo; and Thoratec Corporation, ${ }^{\mathrm{j}}$ Pleasanton, Calif.

Disclosures: Jeffrey Teuteberg, Stuart Russell, Leslie Miller, and Todd Massey report consulting/lecture fees and grant support from Thoratec. Francis Pagani reports grant support from Thoratec. David Farrer reports grant support, equity, and employment by Thoratec.

Received for publication July 30, 2009; revisions received Oct 17, 2009; accepted for publication Nov 12, 2009; available ahead of print Feb 4, 2010.

Address for reprints: Robert L. Kormos, MD, FRCS, FACS, FAHA, Artificial Heart Program, Co-Director Heart Transplantation, 200 Lothrop St, Suite C-800, Pittsburgh, PA 15213 (E-mail: kormosrl@upmc.edu).

$0022-5223 / \$ 36.00$

Copyright (c) 2010 by The American Association for Thoracic Surgery doi:10.1016/j.jtcvs.2009.11.020
}

insufficient. ${ }^{1}$ Although cardiac transplantation remains an attractive therapeutic option for select patients, only 2000 heart transplantations are performed each year in the United States, largely as a result of donor shortages. ${ }^{2}$ This continued limitation underscores the need for alternative avenues of treatment for this patient cohort.

Mechanical circulatory support, and more specifically left ventricular assist devices (LVADs), can be used in this setting as a bridge to transplantation (BTT), as destination therapy for patients who are not suitable for transplantation, and as temporary support for patients whose cardiac function is expected to recover. However, outcomes of patients are critically dependent on right ventricular (RV) function, which must provide sufficient flow through the pulmonary vasculature to fill the LVAD and ensure optimal performance. The physiology of right ventricular failure (RVF) in patients with LVADs has been evaluated previously, and the role of septal position and movement secondary to LVAD assistance was demonstrated as a potential mechanism for RVF, which is 


$\begin{array}{ll}\text { Abbreviations and Acronyms } \\ \text { BiVAD } & =\text { biventricular assist device } \\ \text { BTT } & =\text { bridge to transplantation } \\ \text { BUN } & =\text { blood urea nitrogen } \\ \text { CI } & =\text { confidence interval } \\ \text { CVP } & =\text { central venous pressure } \\ \text { IABP } & =\text { intra-aortic balloon pump } \\ \text { LVAD } & =\text { left ventricular assist device } \\ \text { MRVFRS } & =\text { University of Michigan right ventricular } \\ & \text { failure risk score } \\ \text { OR } & =\text { odds ratio } \\ \text { PCWP } & =\text { pulmonary capillary wedge pressure } \\ \text { RV } & =\text { right ventricular } \\ \text { RVAD } & =\text { right ventricular assist device } \\ \text { RVF } & =\text { right ventricular failure } \\ \text { RVSWI } & =\text { right ventricular stroke work index } \\ \text { VAD } & =\text { ventricular assist device } \\ \text { WBC } & =\text { white blood cell count }\end{array}$

counterbalanced by significant reductions in RV afterload and pulmonary pressures. ${ }^{3,4}$ However, these mechanisms were derived mostly from the study of pulsatile LVADs, and there is a question about whether these precepts are still applicable for continuous-flow pumps.

The development of RVF in patients with an LVAD has a direct effect on mortality and is associated with prolonged length of intensive care unit and hospital stay. ${ }^{5-10}$ Patients with severe RVF requiring biventricular assist devices (BiVADs) have been shown to be more severely ill, with significantly higher preoperative creatinine levels, total bilirubin levels, and need for intra-aortic balloon pump (IABP) support than patients who were adequately supported with isolated LVADs. ${ }^{11}$ Furthermore, RVF in patients with LVADs leads to increased morbidity, including end-organ dysfunction, ${ }^{8,11}$ which can deteriorate further after LVAD implantation, resulting in poor outcomes after cardiac transplantation. ${ }^{12}$ With proper identification of patients at high risk for RVF, planned use of paracorporeal BiVADs might be appropriate in such patients. ${ }^{13,14}$ Temporary right ventricular assist devices (RVADs) can also be used in conjunction with chronic LVADs for patients who are identified as only needing a few days or weeks of RV support. Consequently, recent studies have attempted to ascertain univariate, ${ }^{8,15}$ as well as multivariate, ${ }^{16}$ predictors of RVF to identify patients at risk for RVF after LVAD implantation. Preoperative identification of such patients might help in pre-emptive placement of RVADs, which could improve overall VAD outcomes. ${ }^{13}$

Most of the current studies describing RVF in patients with LVADs are either limited by a small sample size or a single-center experience or were done on earlier-generation pulsatile devices. ${ }^{8,9,15,17}$ The incidence of the need for
RVADs and extended inotropic support have been published for the initial HeartMate II (Thoratec, Pleasanton, Calif) trial results. ${ }^{18,19}$ However, a detailed analysis of multicenter data for the risks of RVF with the continuous-flow devices has not been established for a large group of patients. The aim of this study was to evaluate the incidence, risk factors, and effect on outcomes of RVF in patients implanted with the HeartMate II continuous-flow LVAD.

\section{MATERIALS AND METHODS \\ Study Design}

Data were analyzed from the multicenter HeartMate II pivotal clinical trial for BTT. Details of the study design and trial results have been previously published for the initial 133 patients, ${ }^{18}$ and updated results have been published for 281 patients. ${ }^{19}$ Between March 2005 and April 2008, the total enrollment reached 484 patients at 36 centers, and these patients were included in this analysis. Patients listed as status $1 \mathrm{~A}$ or $1 \mathrm{~B}$ on the heart transplant list were implanted with the HeartMate II LVAD, and survival to transplantation, actuarial survival, functional status, quality of life, and adverse events were determined. All adverse events, including RVF, were adjudicated by an independent clinical events committee.

RVF was defined in the HeartMate II clinical trial as either the need for an RVAD in addition to the LVAD (group 1), continuous inotropic support for at least 14 days after implantation (group 2), or late inotropic support starting 14 days after implantation (group 3). Data from groups 1 and 2 were combined to form an early RVF group, whereas group 3 patients were examined separately (late RVF group). The rationale for differentiating early and late occurrences of RVF is that the cause of the RVF is likely triggered by different mechanisms. Baseline preoperative demographic clinical, hemodynamic, and laboratory data were compared between patients with early RVF (groups 1 and 2) and patients without RVF to identify potential predisposing risk factors. The effect of RVF on survival to transplantation, recovery, or continuing support at 180 days after implantation and on Kaplan-Meier actuarial survival was also determined.

Data analyzed included patients' characteristics and demographics (age, sex, cause of heart failure, and body surface area), baseline hemodynamics (cardiac index, pulmonary capillary wedge pressure [PCWP], mean pulmonary artery pressure, systolic pulmonary artery pressure, diastolic pulmonary artery pressure, central venous pressure [CVP], CVP/PCWP ratio, ${ }^{20}$ right ventricular stroke work index [RVSWI], systolic blood pressure, left ventricular ejection fraction, and left ventricular end-diastolic volume), use of an IABP or ventilator support, laboratory data (blood urea nitrogen [BUN], creatinine, alanine aminotransferase, total bilirubin, hematocrit, white blood cell count [WBC], platelet count, and international normalized ratio), and postoperative bleeding and transfusion requirements. The University of Michigan RVF risk score (MRVFRS) was calculated based on the formula provided by Matthews and colleagues. ${ }^{16}$

\section{Statistical Analysis}

Differences between measures of continuous variables with and without RVF were analyzed by using the independent-samples $t$ test for normal data and the Mann-Whitney $U$ test for nonnormal data. For multiple groups (no RVF vs RVF-RVAD [group 1] vs RVF-continuous inotropic support for $\geq 14$ days after implantation [group 2] vs RVF-late inotropic support starting 14 days after implantation [group 3]), single-factor analysis of variance was performed. When the residuals were not normally distributed, the KruskalWallis multiple-comparisons test was performed instead. For categoric variables, Fisher's exact test was used for comparing 2 groups, and Pearson's $\chi^{2}$ test was used for more than 2 groups. All statistical comparisons were 2 -sided. Univariate logistic regression was performed on all variables to identify the potential risk factors for early RVF, followed by stepwise forward multivariate logistic regression on the univariate predictors, with an entry criterion 
of a $P$ value of less than.1. Survival analysis for patients continuing on mechanical support was performed with the Kaplan-Meier method. Differences in actuarial survival were evaluated by using the log-rank test. Patients were censored for transplantation, recovery of the native heart, and withdrawal from the study. All continuous parameters were first dichotomized at the 25th, 33rd, 50th, 66th, and 75th percentiles, and the percentile value with the lowest $P$ value was chosen as the threshold for the analysis. The dichotomization took place at the 25th (BSA and hematocrit), 50th (mean pulmonary artery pressure and systolic pulmonary artery pressure), 66th (CVP), and 75th (CVP/PCWP, creatinine, BUN, AST, and WBC) percentiles. For RVSWI, the threshold was set at $300 \mathrm{~mm} \mathrm{Hg} \cdot \mathrm{mL} \cdot \mathrm{m}^{-2}$, which has previously been shown to be a critical value for RVAD implantation. ${ }^{21}$ The MRVFRS was dichotomized based on the critical value previously proposed by Matthews and colleagues. ${ }^{16}$ Biochemical and hemodynamic variables are presented as means \pm standard deviations, and categoric variables are presented as percentages. All statistical analyses were done with SYSTAT (Cranes Software, Chicago, Ill).

\section{RESULTS}

\section{Baseline Characteristics and RVF Incidence}

Baseline data and comparisons between groups are summarized in Table 1. A total of $98(20 \%)$ of the 484 patients had some form of RVF according to trial definitions. This included $30(6 \%)$ patients requiring an RVAD (group 1), 35 $(7 \%)$ patients requiring at least 14 days of continuous inotropic support after implantation (group 2), and 33 (7\%) patients requiring late inotropic support starting after the 14th day (group 3). Demographic and hemodynamic data were typical of patients with advanced heart failure and were similar between patients with early RVF and patients without $\mathrm{RVF}$, with the following notable exceptions: baseline CVP was significantly higher in patients with early RVF (15.0 $\pm 7.0 \mathrm{~mm} \mathrm{Hg}$ ), especially for patients requiring RVADs $(16.1 \pm 6.4 \mathrm{~mm} \mathrm{Hg})$, when compared with those without $\mathrm{RVF}(12.3 \pm 6.4 \mathrm{~mm} \mathrm{Hg}, P=.002)$. Similarly, the CVP/ PCWP ratio was significantly higher for the early RVF groups compared with the no-RVF group $(0.60 \pm 0.20$ vs $0.51 \pm 0.46$ ), and mean RVSWI was significantly lower for the early RVF group ( $477 \pm 306$ vs $556 \pm 298 \mathrm{~mm}$ $\left.\mathrm{Hg} \cdot \mathrm{mL}^{-1} \cdot \mathrm{m}^{-2}, P=.03\right)$. Furthermore, more than $30 \%$ of

TABLE 1. Preimplantation characteristics for all groups

\begin{tabular}{|c|c|c|c|c|c|c|}
\hline & \multirow[b]{2}{*}{$\begin{array}{l}\text { No RVF } \\
(n=386)\end{array}$} & \multicolumn{3}{|c|}{ RVF subgroups } & \multirow[b]{2}{*}{$\boldsymbol{P}$ value $\S$} & \multirow[b]{2}{*}{$\begin{array}{c}\text { Any early RVF } \\
(n=65)\end{array}$} \\
\hline & & $\begin{array}{c}\text { RVF-RVAD } \\
(\mathbf{n}=\mathbf{3 0})\end{array}$ & $\begin{array}{l}\text { RVF-early inotropes } \\
\quad(n=35)\end{array}$ & $\begin{array}{c}\text { RVF-late inotropes } \\
\quad(\mathbf{n}=\mathbf{3 3})\end{array}$ & & \\
\hline $\begin{array}{l}\text { Percentage of total patients } \\
\quad(\mathrm{n}=484)\end{array}$ & 80 & 6 & 7 & 7 & - & 13 \\
\hline Female sex & $80(21 \%)$ & $7(23 \%)$ & $8(23 \%)$ & $13(39 \%)$ & .1 & $15(23 \%)$ \\
\hline Ischemic cause & $174(45 \%)$ & $15(50 \%)$ & $15(43 \%)$ & $10(30 \%)$ & .37 & $30(46 \%)$ \\
\hline Age (y) & $51.8 \pm 13.5$ & $51.0 \pm 13.3$ & $55.0 \pm 11.0$ & $48.6 \pm 12.0$ & .12 & $53.0 \pm 12.0$ \\
\hline BSA & $1.99 \pm 0.26$ & $1.94 \pm 0.28$ & $1.98 \pm 0.30$ & $2.11 \pm 0.63$ & .58 & $1.96 \pm 0.29$ \\
\hline CI & $2.1 \pm 0.7$ & $2.0 \pm 0.6$ & $2.2 \pm 0.8$ & $2.0 \pm 0.5$ & .96 & $2.1 \pm 0.7$ \\
\hline PCWP $(\mathrm{mm} \mathrm{Hg})$ & $25 \pm 8$ & $26 \pm 8$ & $26 \pm 8$ & $24 \pm 7$ & .6 & $26 \pm 6$ \\
\hline PAPm (mm Hg) & $36 \pm 9$ & $35 \pm 9$ & $35 \pm 9$ & $35 \pm 11$ & .94 & $35 \pm 9$ \\
\hline PAPs (mm Hg) & $52 \pm 13$ & $49 \pm 12$ & $50 \pm 16$ & $50 \pm 17$ & .54 & $50 \pm 14$ \\
\hline PAPd (mm Hg) & $27 \pm 8$ & $27 \pm 8$ & $26 \pm 8$ & $26 \pm 9$ & .87 & $27 \pm 8$ \\
\hline $\mathrm{CVP}(\mathrm{mm} \mathrm{Hg})$ & $12.3 \pm 6.4$ & $16.1 \pm 6.4 \dagger$ & $14.5 \pm 7.1^{*}$ & $12.9 \pm 7.7$ & .01 & $15.2 \pm 6.8 \dagger$ \\
\hline CVP/PCWP ratio & $0.51 \pm 0.46$ & $0.64 \pm 0.21$ & $0.57 \pm 0.27$ & $0.51 \pm 0.23$ & .1 & $0.60 \pm 0.20 \ddagger$ \\
\hline RVSWI $\left(\mathrm{mm} \mathrm{Hg} \cdot \mathrm{mL} \cdot \mathrm{m}^{-2}\right)$ & $556 \pm 298$ & $391 \pm 226^{*}$ & $541 \pm 344.1$ & $560 \pm 335$ & .04 & $477 \pm 306^{*}$ \\
\hline PVR (Wood Units) & $2.91 \pm 1.61$ & $2.93 \pm 1.41$ & $2.79 \pm 1.55$ & $2.94 \pm 1.67$ & .97 & $2.85 \pm 1.48$ \\
\hline BPs (mm Hg) & $99 \pm 16$ & $102 \pm 18$ & $98 \pm 15$ & $95 \pm 14$ & .51 & $100 \pm 16$ \\
\hline Heart rate (beats/min) & $91 \pm 19$ & $98 \pm 19$ & $89 \pm 17$ & $87 \pm 19$ & .14 & $93 \pm 18$ \\
\hline IABP & $161(42 \%)$ & $18(60 \%)$ & $15(43 \%)$ & $9(27 \%)$ & .07 & $33(51 \%)$ \\
\hline Ventilatory support & $21(5 \%)$ & $11(37 \%) \ddagger$ & $5(14 \%)^{*}$ & $3(9 \%)$ & $<.001$ & $16(25 \%) \ddagger$ \\
\hline Pacing & $188(49 \%)$ & $10(33 \%)$ & $20(57 \%)$ & $18(55 \%)$ & .23 & $30(46 \%)$ \\
\hline Creatinine (mg/dL) & $1.41 \pm 0.50$ & $1.54 \pm 0.52$ & $1.53 \pm 0.59$ & $1.47 \pm 0.63$ & .34 & $1.53 \pm 0.56$ \\
\hline BUN (mg/dL) & $29.6 \pm 16.6$ & $36.1 \pm 17.5^{*}$ & $32.0 \pm 13.6$ & $33.1 \pm 19.7$ & .05 & $33.8 \pm 15.0^{*}$ \\
\hline AST (mg/dL) & $74 \pm 201$ & $236 \pm 557 \dagger$ & $78 \pm 236$ & $89 \pm 164^{*}$ & .02 & $148 \pm 415$ \\
\hline TBILI (mg/dL) & $1.25 \pm 0.78$ & $1.39 \pm 1.43$ & $1.34 \pm 0.71$ & $1.25 \pm 0.98$ & .55 & $1.36 \pm 1.07$ \\
\hline $\operatorname{HCT}(\%)$ & $34.9 \pm 5.5$ & $33.5 \pm 7.4$ & $35.3 \pm 6.0$ & $34.5 \pm 5.4$ & .26 & $4.5 \pm 6.6$ \\
\hline $\mathrm{WBC}\left(\times 10^{3} / \mathrm{mL}\right)$ & $8.7 \pm 3.6$ & $11.2 \pm 4.6 \dagger$ & $9.3 \pm 3.2$ & $8.4 \pm 3.2$ & .01 & $10.1 \pm 4.0 \dagger$ \\
\hline $\operatorname{PLT}\left(\times 10^{3} / \mathrm{mL}\right)$ & $226 \pm 88$ & $221 \pm 90$ & $220 \pm 74$ & $225 \pm 93$ & .98 & $220 \pm 81$ \\
\hline INR (International Units) & $1.32 \pm 0.33$ & $1.57 \pm 1.01$ & $1.35 \pm 0.32$ & $1.37 \pm 0.44$ & .89 & $1.5 \pm 0.71$ \\
\hline MRVFRS & $1.14 \pm 1.88$ & $2.04 \pm 2.34$ & $1.34 \pm 1.70$ & $1.38 \pm 1.80$ & .08 & $1.65 \pm 2.00 *$ \\
\hline
\end{tabular}

$R V F$, Right ventricular failure; $R V A D$, right ventricular assist device; $B S A$, body surface area; $C I$, cardiac index; $P C W P$, pulmonary capillary wedge pressure; $P A P m$, mean pulmonary artery pressure; $P A P s$, systolic pulmonary artery pressure; $P A P d$, diastolic pulmonary artery pressure; $C V P$, central venous pressure; $R V S W I$, right ventricular stroke work index; $B P s$, systolic blood pressure; IABP, intra-aortic balloon pump; $B U N$, blood urea nitrogen; $A S T$, aspartate aminotransferase; TBILI, total bilirubin; $H C T$, hematocrit; $W B C$, white blood count; $P L T$, platelet count; $I N R$, international normalized ratio; $M R V F R S$, University of Michigan right ventricular failure risk score. ${ }^{*} P<.05, \dagger P<.01$, and $\ddagger P<.001$ compared with no-RVF group. $\S P$ value for differences between the 4 subgroups. 
patients with early RVF ( $>50 \%$ of those requiring RVADs) had an RVSWI of less than $300 \mathrm{~mm} \mathrm{Hg} \cdot \mathrm{mL} \cdot \mathrm{m}^{-2}$ compared with $16 \%$ of patients without RVF.

For baseline laboratory data, preoperative WBC (10.1 \pm 4.0 vs $\left.8.7 \pm 3.6 \times 10^{3} / \mathrm{mL}, P=.004\right)$ and BUN $(33.8 \pm$ 15.0 vs $29.6 \pm 16.6 \mathrm{mg} / \mathrm{dL}, P=.01)$ values were significantly higher for those with early RVF compared with values in those without RVF (Table 1). These values were further increased for patients requiring an RVAD, in whom the WBC $\left(11.2 \pm 4.6\right.$ vs $8.7 \pm 3.6 \times 10^{3} / \mathrm{mL}, P<$ $.05)$ and BUN $(36.1 \pm 17.5$ vs $29.6 \pm 16.6, P<.05)$ values were significantly higher than those in patients with no RVF. A significantly higher proportion of the few patients $(\mathrm{n}=$ 40) on ventilator support before HeartMate II implantation had early RVF compared with those who were not $(40 \%$ vs $11 \%, P<.001), 28 \%$ of whom required an RVAD. Finally, the AST value was significantly higher in those requiring an RVAD compared with that seen in those who did not have $\operatorname{RVF}(236 \pm 557$ v $74 \pm 201 \mathrm{mg} / \mathrm{dL}, P<.03)$. Patients with early RVF had a higher MRVFRS $(1.65 \pm 2.00$ vs 1.14 $\pm 1.88, P<.02$ ), whereas there was no significant difference between the corresponding RVF subgroups.

Of the patients who were started on an RVAD, 14 received a Centrimag (Levitronix, Waltham, Mass), 9 received an Abiomed (Abiomed, Danvers, Mass), 3 received a Tandem Heart (Cardiac Assist, Pittsburgh, Pa), and 4 received a Thoratec paracorporeal VAD (Thoratec, Pleasanton, Calif) (Table 2). Most RVADs were implanted within the first 24 hours of LVAD surgery. Eight patients received an RVAD after 24 hours, with 1 patient receiving an RVAD 38 days after LVAD surgery. Three of these 8 patients underwent transplantation, 4 died, and 1 was withdrawn. Durations of support for all RVADs ranged from 0 to 408 days.

\section{Clinical Outcome}

In patients without RVF, $342(89 \%)$ survived to transplantation, recovery, or continuing support at 180 days (Table 3). Patients with early RVF had significantly worse survival to the same end points $(\mathrm{n}=46,71 \% ; P=.001)$, with those requiring RVADs having the lowest percentage reaching these outcomes $(\mathrm{n}=20,67 \% ; P<.001)$. Within the RVAD group, $17(77 \%)$ of 22 patients who received an RVAD within the first 24 hours survived to the primary outcome at 180 days, whereas only $3(39 \%)$ of 8 patients who received an RVAD later survived to the same end point. Actuarial survival at 1 year was also significantly better for patients without RVF (79\%) compared with that in patients requiring RVADs (group $1,59 \% ; P=.004$ ) or extended inotropes (group $2,56 \% ; P=.007$ ), whereas there was no difference for patients with late inotrope use (group 3, $75 \% ; P=.81)$. Decreased survival for patients with early RVF is evident in the grouped Kaplan-Meier survival curve (Figure 1).

Hospital length of stay for discharged patients was longer for those requiring an RVAD than for those without RVF (32 vs 22 days, $P<.001$ ). Those who required inotropic support for more than 14 days after LVAD implantation and those with late inotropic support had an average length of stay of 35 and 32 days, respectively. Thus any RVF resulted in a significantly longer hospitalization time before discharge than seen in those without any $\operatorname{RVF}(P<.001)$.

\section{Univariate and Multivariate Preoperative Risk Factors}

Univariate analyses of predictors of RVF are shown in Table 4 , and the associated relative risk ratios are depicted in Figure 2. The hemodynamic variables of CVP greater than $15 \mathrm{~mm} \mathrm{Hg}$, RVSWI less than $300 \mathrm{~mm} \mathrm{Hg} \cdot \mathrm{mL} \cdot \mathrm{m}^{-2}$, and a CVP/PCWP ratio greater than 0.63 were statistically significant predictors that indicated a higher risk of RVF. There were no statistically significant differences in pulmonary artery pressures or pulmonary vascular resistance between groups. With a baseline CVP of greater than $15 \mathrm{~mm} \mathrm{Hg}$, $19 \%$ of patients had early RVF compared with $10 \%$ of patients with a CVP of less than $15 \mathrm{~mm} \mathrm{Hg}$ (odds ratio [OR], $2.1 ; 95 \%$ confidence interval $[\mathrm{CI}], 1.2-3.6 ; P<.01)$. Similarly $22 \%$ of patients with a CVP/PCWP ratio of greater than 0.63 had early RVF compared with $11 \%$ with a CVP/ PCWP ratio of less than 0.63 , and $26 \%$ of patients with an RVSWI of less than $300 \mathrm{~mm} \mathrm{Hg} \cdot \mathrm{mL} \cdot \mathrm{m}^{-2}$ had RVF compared with $10 \%$ of patients with an RVSWI of greater than $300 \mathrm{~mm} \mathrm{Hg} \cdot \mathrm{mL} \cdot \mathrm{m}^{-2}$. Increased WBC and lower hematocrit values were also statistically significant between those who required RVAD support and those who did not. Patients on preoperative ventilator support were 5 times more likely to have RVF compared with those without ventilator support.

TABLE 2. Patients requiring RVADs

\begin{tabular}{|c|c|c|c|c|}
\hline & No. & Day implanted* & Duration of use (d) & $\begin{array}{l}\text { Outcome: transplanted or } \\
\text { ongoing support at } 180 \mathrm{~d}\end{array}$ \\
\hline \multicolumn{5}{|l|}{ RVADs } \\
\hline Centrimag & 14 & $0(0-2)$ & $17(6-148)$ & $79 \%$ \\
\hline Paracoporeal VAD & 4 & $2(0-15)$ & $8(0-50)$ & $75 \%$ \\
\hline Abiomed & 9 & $0(0-10)$ & $5(0-408)$ & $44 \%$ \\
\hline Tandem Heart & 3 & $0(0-38)$ & $25(7-106)$ & $66 \%$ \\
\hline Total & 30 & $0(0-38)$ & $13(0-408)$ & $67 \%$ \\
\hline
\end{tabular}

RVADs, Right ventricular assist devices. *Median and ranges. 
TABLE 3. Outcomes

\begin{tabular}{|c|c|c|c|c|}
\hline & Patients $(n=484)$ & $\begin{array}{c}\text { Length of stay for } \\
\text { discharged patients (d) }\end{array}$ & $\begin{array}{l}\text { Transplant, recovery, } \\
\text { or ongoing at } 180 \mathrm{~d}\end{array}$ & $\begin{array}{l}\text { Kaplan-Meier } \\
\text { survival at } 1 \text { y }\end{array}$ \\
\hline No RVF & $386(80 \%)$ & $22(8-180)$ & $342(89 \%)$ & $78 \% \pm 3 \%$ \\
\hline \multicolumn{5}{|l|}{ RVF subgroups } \\
\hline RVAD & $30(6 \%)$ & $32(0-158) \ddagger$ & $20(67 \%) \dagger$ & $59 \% \pm 9 \% \dagger$ \\
\hline Inotropes, early & $35(7 \%)$ & $35(17-73) \ddagger$ & $25(71 \%)^{*}$ & $56 \% \pm 9 \% \dagger$ \\
\hline Inotropes, late & $33(7 \%)$ & $32(12-86) \ddagger$ & $29(88 \%)$ & $75 \% \pm 9 \%$ \\
\hline Any early RVF & $65(13 \%)$ & $32(0-173) \ddagger$ & $46(71 \%) \ddagger$ & $59 \% \pm 7 \% \dagger$ \\
\hline
\end{tabular}

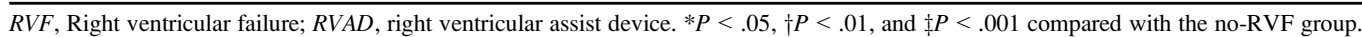

Increased MRVFRSs, creatinine values, or AST values were not statistically significant predictors of RVF.

Multivariate analysis revealed that a CVP/PCWP ratio of greater than 0.63 (OR, 2.3; 95\% CI, 1.2-4.3; $P<.009]$ ), need for ventilatory support (OR, 5.5; 95\% CI, 2.3-13.2; $P<.001$ ), and a preoperative BUN value of greater than $39 \mathrm{mg} / \mathrm{dL}(\mathrm{OR}, 2.1 ; 95 \% \mathrm{CI}, 1.1-4.1 ; P<.02)$ were the significant independent preoperative predictors of early RVF after LVAD implantation. The area under the receiver operating curve was 0.68 , which is comparable with that seen in earlier risk models of RVF. ${ }^{16}$

\section{Intraoperative and Postoperative Factors}

There were no significant differences in bleeding and transfusion requirements during implantation or within the first 48 hours of LVAD implantation (Table 5) for those who eventually had RVF. However, patients implanted with an RVAD required a greater number of units of packed red blood cell transfusions compared with those without $\operatorname{RVF}(14.3 \pm 18.9$ vs $5.6 \pm 5.8$ units, $P<.03)$ and more often required a reoperation for bleeding $(40 \%$ vs $19 \%, P<$ $.04)$. Fifty-three percent of patients who needed an RVAD required greater than 6 units of packed red blood cells during

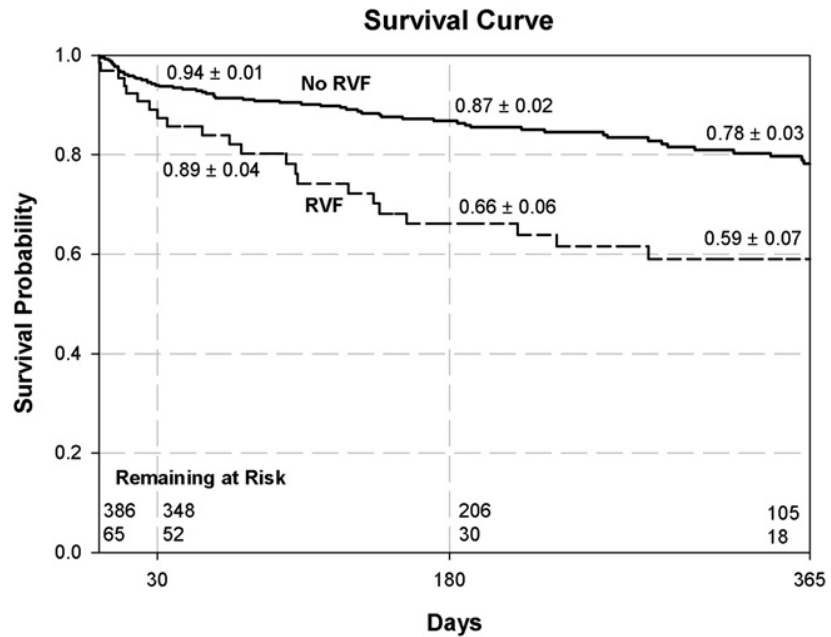

FIGURE 1. Kaplan-Meier survival for patients with and without early RVF receiving the HeartMate II LVAD, which includes the need for RVADs or extended inotropic support for more than 14 days. the implantation procedure, whereas only $26 \%$ of those without RVF required similar levels of transfusion. Cardiopulmonary bypass times were higher in those who required an RVAD (149 \pm 76 vs $106 \pm 61$ minutes, $P<.005$ ), which is likely attributable to the additional surgical procedures required to implant an RVAD.

\section{DISCUSSION}

Patients receiving the HeartMate II continuous-flow LVAD as a BTT demonstrated a $6 \%$ incidence of RVF requiring an RVAD and a 7\% incidence of extended inotropic support, for an overall incidence of early RVF of $13 \%$. Patients receiving the HeartMate II with early RVF had a $20 \%$ reduction in 1-year survival compared with that seen in patients who did not have RVF. In addition, patients requiring inotropic agents starting 14 days after LVAD implantation did not have a reduction in survival, although their length of hospital stay was increased. The overall incidence of early RVF seems to have decreased from those reported previously, ${ }^{8,9,11}$ which can be attributed to the improved patient selection and optimization of the right heart before LVAD implantation. The presence of RVF of any sort was associated with longer cardiopulmonary bypass times during surgical intervention and the subsequent need for blood transfusions, with the highest values in patients requiring an RVAD. RVSWI, increased preimplantation CVP, increased preimplantation CVP/PCWP ratio, and impaired renal or respiratory function also appear to predispose to the need for an RVAD after LVAD implantation.

Several previous studies have attempted to understand the mechanism leading to RVF in LVAD recipients, and numerous conflicting reports contest to the complex host of variables at play in this setting. One of the more common explanations is that the acute unloading of the left heart ventricle leads to a septal shift that alters RV shape and size, thereby affecting its contractility. ${ }^{3,4,22}$ In addition, pre-existing RV impairment might be unmasked with the increase in right-sided preload afforded by LVAD perfusion. ${ }^{4,8}$ These aspects are now being routinely considered at the time of LVAD and when deciding on device settings to keep the septal shift to a minimum.

There is a common misconception that the reduced survival rate in patients requiring biventricular support is due 


\begin{tabular}{|c|c|c|c|c|c|c|}
\hline & \multirow[b]{2}{*}{ No RVF } & \multicolumn{3}{|c|}{ RVF subgroups } & \multirow[b]{2}{*}{ Any early RVF } & \multirow[b]{2}{*}{ Odds ratios } \\
\hline & & RVF-RVAD & $\begin{array}{c}\text { RVF-early } \\
\text { inotropes }\end{array}$ & $\begin{array}{l}\text { RVF-late } \\
\text { inotropes }\end{array}$ & & \\
\hline Female sex $(n=108)$ & $80(74 \%)$ & $7(6 \%)$ & $8(7 \%)$ & $13(12 \%)$ & $15(13 \%)$ & $1.15(0.60-2.20)^{*}$ \\
\hline Male sex $(n=376)$ & $306(81 \%)$ & $23(6 \%)$ & $27(7 \%)$ & $20(5 \%)$ & $50(13 \%)$ & \\
\hline $\mathrm{BSA}>1.8(\mathrm{n}=351)$ & $286(82 \%)$ & $20(6 \%)$ & $22(6 \%)$ & $23(6 \%)$ & $42(12 \%)$ & $1.56(0.90-2.70)^{*}$ \\
\hline $\mathrm{BSA} \leq 1.8(\mathrm{n}=133)$ & $100(75 \%)$ & $10(7.5 \%)$ & $13(10 \%)$ & $10(7.5 \%)$ & $23(17 \%)$ & \\
\hline PAPm >36 mm Hg $(\mathrm{n}=217)$ & $181(83 \%)$ & $8(4 \%)$ & $14(6 \%)$ & $14(6 \%)$ & $22(10 \%)$ & $1.7(1.00-3.00)^{*}$ \\
\hline $\mathrm{PAPm} \leq 36 \mathrm{~mm} \mathrm{Hg}(\mathrm{n}=261)$ & $205(77 \%)$ & $22(8 \%)$ & $21(8 \%)$ & $19(7 \%)$ & $43(16 \%)$ & \\
\hline PAPs $>52 \mathrm{~mm} \mathrm{Hg}(\mathrm{n}=221)$ & $185(84 \%)$ & $10(5 \%)$ & $13(6 \%)$ & $13(6 \%)$ & $23(10 \%)$ & $1.7(0.97-2.90)$ \\
\hline PAPs $\leq 52 \mathrm{~mm} \mathrm{Hg}(\mathrm{n}=263)$ & $201(76 \%)$ & $20(8 \%)$ & $22(8 \%)$ & $20(8 \%)$ & $42(16 \%)$ & \\
\hline $\mathrm{CVP}>15 \mathrm{~mm} \mathrm{Hg}(\mathrm{n}=176)$ & $129(73 \%)$ & $16(9 \%) \dagger$ & $17(10 \%)$ & $14(8 \%)$ & $33(19 \%) \ddagger$ & $2.1(1.20-3.60)$ \\
\hline $\mathrm{CVP} \leq 15 \mathrm{~mm} \mathrm{Hg}(\mathrm{n}=282)$ & $236(84 \%)$ & $12(4 \%)$ & $17(6 \%)$ & $17(6 \%)$ & $29(10 \%)$ & \\
\hline CVP/PCWP $>0.63(n=98)$ & $67(68 \%)$ & $10(10 \%) \dagger$ & $12(12 \%) \dagger$ & $9(9 \%)$ & $22(22 \%) \ddagger$ & $2.5(1.37-4.60)^{*}$ \\
\hline CVP/PCWP $\leq 0.63(\mathrm{n}=302)$ & $251(83 \%)$ & $14(5 \%)$ & $19(6 \%)$ & $18(6 \%)$ & $33(11 \%)$ & \\
\hline $\begin{array}{l}\text { RVSWI }>300 \mathrm{~mm} \\
\mathrm{Hg} \cdot \mathrm{mL} \cdot \mathrm{m}^{-2}(\mathrm{n}=347)\end{array}$ & $285(82 \%)$ & $11(3 \%)$ & $25(7 \%)$ & $26(7 \%)$ & $36(10 \%)$ & $2.9(1.60-5.30)$ \\
\hline $\begin{array}{l}\mathrm{RVSWI} \leq 300 \mathrm{~mm} \\
\mathrm{Hg} \cdot \mathrm{mL} \cdot \mathrm{m}^{-2}(\mathrm{n}=78)\end{array}$ & $55(70 \%)$ & $13(17 \%) \ddagger$ & $7(9 \%)$ & $3(4 \%)$ & $20(26 \%) \S$ & \\
\hline $\begin{array}{l}\text { Ventilatory Support } \\
\qquad(+)(\mathrm{n}=40)\end{array}$ & $21(52.5 \%)$ & $11(28 \%) \ddagger$ & $5(12.5 \%) \ddagger$ & $3(7.5 \%)$ & $16(40 \%) \S$ & $5.7(2.80-11.60)^{*}$ \\
\hline $\begin{array}{l}\text { Ventilatory Support } \\
(-)(\mathrm{n}=444)\end{array}$ & $365(82.2 \%)$ & $19(4 \%)$ & $30(7 \%)$ & $30(7 \%)$ & $49(11 \%)$ & \\
\hline $\begin{array}{l}\text { Creatinine }>1.7 \mathrm{mg} / \mathrm{dL} \\
\quad(\mathrm{n}=118)\end{array}$ & $88(75 \%)$ & $10(8 \%)$ & $11(9 \%)$ & $9(8 \%)$ & $21(18 \%)$ & $1.6(0.90-2.90)^{*}$ \\
\hline $\begin{array}{l}\text { Creatinine } \leq 1.7 \mathrm{mg} / \mathrm{dL} \\
\quad(\mathrm{n}=366)\end{array}$ & $298(81 \%)$ & $20(5 \%)$ & $24(7 \%)$ & $24(7 \%)$ & $44(12 \%)$ & \\
\hline $\mathrm{BUN}>39 \mathrm{mg} / \mathrm{dL}(\mathrm{n}=118)$ & $87(74 \%)$ & $11(9 \%)$ & $11(9 \%)$ & $9(8 \%)$ & $22(19 \%) \dagger$ & $1.7(1.00-3.10)^{*}$ \\
\hline $\mathrm{BUN} \leq 39 \mathrm{mg} / \mathrm{dL}(\mathrm{n}=366)$ & $299(82 \%)$ & $19(5 \%)$ & $24(7 \%)$ & $24(7 \%)$ & $42(12 \%)$ & \\
\hline AST $>49$ mg/dL $(n=118)$ & $88(74.6 \%)$ & $14(12 \%) \dagger$ & $8(7 \%)$ & $8(7 \%)$ & $22(19 \%)$ & $1.73(0.98-3.00)^{*}$ \\
\hline $\mathrm{AST} \leq 49 \mathrm{mg} / \mathrm{dL}(\mathrm{n}=366)$ & $298(81 \%)$ & $16(4 \%)$ & $27(7 \%)$ & $25(7 \%)$ & $43(12 \%)$ & \\
\hline HCT $>31 \%(n=353)$ & $290(82 \%)$ & $13(4 \%)$ & $24(7 \%)$ & $26(7 \%)$ & $37(10 \%)$ & $2.3(1.30-3.90)$ \\
\hline $\mathrm{HCT} \leq 31 \%(\mathrm{n}=131)$ & $96(73 \%)$ & $17(13 \%) \S$ & $11(8 \%)$ & $7(5 \%)$ & $28(21 \%) \ddagger$ & \\
\hline $\begin{array}{l}\mathrm{WBC}>10.4 \times 10^{3} / \mathrm{mL} \\
\quad(\mathrm{n}=120)\end{array}$ & $87(73 \%)$ & $15(13 \%)$ & $10(8 \%)$ & $8(7 \%)$ & $25(21 \%)$ & $2.2(1.20-3.70)^{*}$ \\
\hline $\begin{array}{l}\mathrm{WBC} \leq 10.4 \times 10^{3} / \mathrm{mL} \\
\quad(\mathrm{n}=364)\end{array}$ & $299(82 \%)$ & $15(4 \%) \S$ & $25(7 \%)$ & $25(7 \%)$ & $40(11 \%) \ddagger$ & \\
\hline MRVFRS $\geq 5.5(\mathrm{n}=22)$ & $18(82 \%)$ & $3(14 \%)$ & $0(0 \%)$ & $1(5 \%)$ & $3(14 \%)$ & $0.99(0.28-3.50)$ \\
\hline MRVFRS $<5.5(\mathrm{n}=462)$ & $368(80 \%)$ & $27(6 \%)$ & $35(8 \%)$ & $32(7 \%)$ & $62(14 \%)$ & \\
\hline
\end{tabular}

$R V F$, Right ventricular failure; $R V A D$, right ventricular assist device; $B S A$, body surface area; $P A P m$, mean pulmonary artery pressure; $P A P s$, systolic pulmonary artery pressure; $C V P$, central venous pressure; $P C W P$, pulmonary capillary wedge pressure; $R V S W I$, right ventricular stroke work index; $B U N$, blood urea nitrogen; $A S T$, aspartate aminotransferase; $H C T$, hematocrit; $W B C$, white blood count; MRVFRS, University of Michigan right ventricular failure risk score. *Parameters entered into the multivariate model. $\dagger P<.05, \ddagger P$ $<.01$, and ${ }_{\S} P<.001$ compared with the no-RVF group.

to the BiVADs themselves. However, there is ample evidence that the same preoperative risk factors that predispose a patient to RVF are also risk factors for mortality after LVAD support. In more recent studies, laboratory variables associated with pre-LVAD severity of illness, which are indirectly related to RV function (eg, bilirubin, creatinine, ventilatory support, and IABP use) were found to be more strongly associated with the need for biventricular support as opposed to preimplantation hemodynamic variables. ${ }^{11,16,23}$ These variables might be influencing the predisposition to perioperative bleeding, which negatively affects pulmonary flow because of the interstitial edema as- sociated with blood transfusion and lung damage. In another analysis of 245 patients, the need for pre-LVAD circulatory support, female sex, and nonischemic cause were found to independently predict RVF after LVAD placement. ${ }^{9}$ A more recent study evaluating preoperative RV geometry and tricuspid incompetence found these factors to reliably predict RVF in LVAD recipients. ${ }^{24}$ However, limitations, such as small sample sizes, single-center nature, and pump type, have precluded these findings from being applicable to patients implanted with newer continuous-flow devices.

This report is the largest to date analyzing the effect of continuous-flow LVADs on RV function. The primary 


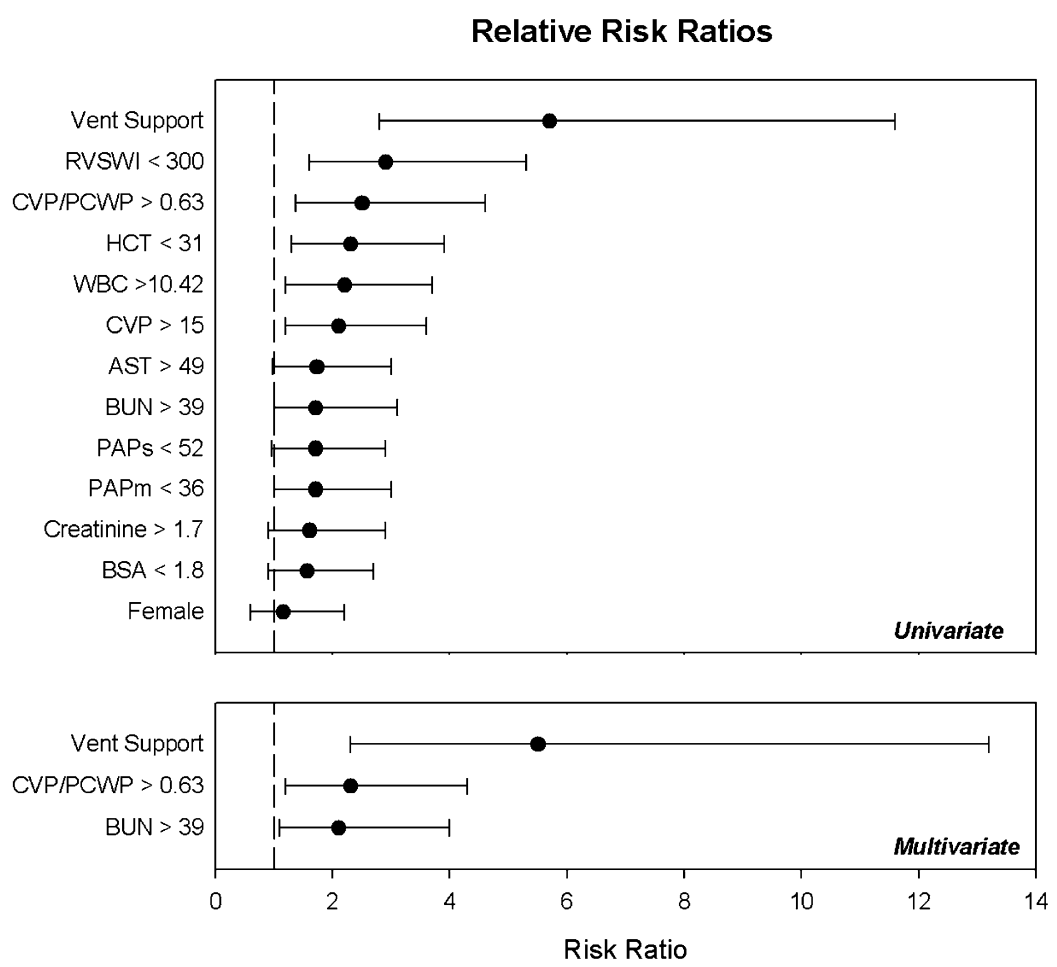

FIGURE 2. Relative risk ratios of univariate and multivariate predictors of RVF during LVAD support.

finding was that a combination of hemodynamic and clinical variables can be used to identify patients who might be at high risk for RVF. A high preoperative WBC, BUN value, and preoperative ventilatory support, along with increased CVP, CVP/PCWP ratio, and decreased RVSWI, were found to be significant univariate predictors of RVF. High CVP and low RVSWI before LVAD implantation can be associated with 2 conditions: worsening right heart function as a result of increased left-sided filling pressures and thus pulmonary hypertension (group A) and intrinsic right heart dysfunction as a result of a progressive myopathic process (group B). The CVP/PCWP ratio was used to better differentiate between patients who fall in group A from those in group B. Hence those with right-sided dysfunction as a result of persistently high left-sided filling pressure would have a low CVP/PCWP ratio, and those with intrinsic $\mathrm{RV}$ dysfunction would have a high $\mathrm{CVP} / \mathrm{PCWP}$ ratio. A CVP/ PCWP ratio of greater than 0.63 , which represents the 75 th percentile of values in the overall population, was in fact an independent multivariate risk factor for RVF, and

TABLE 5. Intraoperative and postoperative characteristics

\begin{tabular}{|c|c|c|c|c|c|c|}
\hline & \multirow[b]{2}{*}{$\begin{array}{c}\text { No RVF } \\
(\mathrm{n}=\mathbf{3 8 6})\end{array}$} & \multicolumn{3}{|c|}{ RVF subgroups } & \multirow[b]{2}{*}{$\boldsymbol{P}$ value $\S$} & \multirow[b]{2}{*}{$\begin{array}{l}\text { Any early RVF } \\
(\mathbf{n}=\mathbf{6 5})\end{array}$} \\
\hline & & $\begin{array}{l}\text { RVF-RVAD } \\
\quad(\mathbf{n}=\mathbf{3 0})\end{array}$ & $\begin{array}{c}\text { RVF-early inotropes } \\
(\mathbf{n}=\mathbf{3 5})\end{array}$ & $\begin{array}{l}\text { RVF-late inotropes } \\
\qquad(\mathbf{n}=\mathbf{3 3})\end{array}$ & & \\
\hline $\begin{array}{l}\text { Percentage of total } \\
\text { patients }(n=484)\end{array}$ & 80 & 6 & 7 & 7 & - & 13 \\
\hline Reoperation for bleeding* & $72(19 \%)$ & $12(40 \%) \dagger$ & $7(20 \%)$ & $9(27 \%)$ & .03 & $19(29 \%)^{*}$ \\
\hline $\begin{array}{l}\text { Bleeding }>2 \text { units } \\
\text { during implantation }\end{array}$ & $269(70 \%)$ & $25(83 \%)$ & $21(60 \%)$ & $20(61 \%)$ & .15 & $46(71 \%)$ \\
\hline $\begin{array}{l}\text { Bleeding }>6 \text { units } \\
\text { during implantation }\end{array}$ & $102(26 \%)$ & $16(53 \%) \dagger$ & $7(20 \%)$ & $8(24 \%)$ & .01 & $13(20 \%)$ \\
\hline Bleeding $>2$ units $<48 \mathrm{~h}$ & $207(54 \%)$ & $15(52 \%)$ & $15(43 \%)$ & $12(38 \%)$ & .19 & $30(46 \%)$ \\
\hline Bleeding $>6$ units $<48 \mathrm{~h}$ & $110(29 \%)$ & $9(31 \%)$ & $7(20 \%)$ & $6(19 \%)$ & .44 & $16(25 \%)$ \\
\hline PRBC during $<48 \mathrm{~h}$ & $5.5 \pm 5.8$ & $14.3 \pm 18.9 *$ & $4.8 \pm 4.8$ & $5.1 \pm 5.7$ & .04 & $8.8 \pm 13.9$ \\
\hline $\begin{array}{l}\text { Cardiopulmonary bypass } \\
\text { time ( } \mathrm{min})\end{array}$ & $106 \pm 61$ & $149 \pm 76 \ddagger$ & $101 \pm 41$ & $99 \pm 40$ & .004 & $124 \pm 64^{*}$ \\
\hline
\end{tabular}

$\overline{R V F}$, Right ventricular failure; $R V A D$, right ventricular assist device; $P R B C$, packed red blood cells. $* P<.05, \dagger P<.01$, and $\ddagger P<.001$ compared with the no-RVF group. $\S P$ value for differences between the 4 subgroups. 
notably, CVP was not. Thus patients with a CVP that approaches the left-sided filling pressure before LVAD might represent the group at highest risk for right heart failure after LVAD implantation. In addition, those who have a lack of $\mathrm{RV}$ contractile reserve and have a relatively greater increase of right-sided filling pressures might have more septal shift and increased venous return, which outweighs any benefits of left ventricular unloading. Identifying such risk factors is clinically relevant because it might help in selecting patients who will benefit from biventricular rather than univentricular support. This is especially important because recent studies have shown that a planned placement of biventricular support results in superior outcomes compared with delayed conversion of LVADs to biventricular support. ${ }^{13}$ Preoperative optimization strategies can also help the right ventricle, for example by reducing the volume status as much as possible before the LVAD implantation.

Although the incidence of RVAD insertion in LVAD recipients has been decreasing as clinical experience with RVF management accumulates, the mortality associated with RVF remains high. ${ }^{5-7,25}$ Moreover, this increased mortality is a direct result of RVF leading to less flow to the LVAD and therefore less pump output and increased venous pressure leading to decreased perfusion to vital organs. The findings of the current study were similar to those of these prior studies in that patients with RVF experienced a lower survival rate to transplantation, recovery, or continuing support at 180 days. These observations again reiterate the need for better selection of patients at high risk for RVF, which might help in preventing its occurrence by providing mechanical assistance to the right side simultaneously with LVAD implantation, as evidenced by improved 180-day survival in patients who received an RVAD within 24 hours of LVAD surgery.

Limitations of this study include its retrospective nature because of which there was no concurrent control group for comparison with pulsatile devices. Results from a randomized comparison of pulsatile and continuous-flow devices will be available at the conclusion of the HeartMate II Destination Therapy clinical trial. Although RVF was comprised of 3 groups, the early inotrope (group 2) and RVAD (group 1) groups exhibited similar survival characteristics, whereas the late inotrope group (group 3) resembled the no-RVF group. For this reason, the late inotrope group (group 3) was excluded from the RVF group for most of the analyses but should be the focus of future studies.

In conclusion, rates of RVF and RVAD requirement in patients with the HeartMate II are low relative to previous results with pulsatile LVADs and support the use of this device in those with end-stage heart failure. Nevertheless, the development of RVF remains difficult to predict, although our data suggest that both clinical and hemodynamic factors affect the development of RVF. RVF in HeartMate II recipients is associated with worse clinical outcomes than in patients without RVF, which underscores the importance of appropriate RVF management and prevention in this patient cohort.

\section{References}

1. Ammar KA, Jacobsen SJ, Mahoney DW, Kors JA, Redfield MM, Burnett JC Jr, et al. Prevalence and prognostic significance of heart failure stages: application of the American College of Cardiology/American Heart Association heart failure staging criteria in the community. Circulation. 2007;115:1563-70.

2. The Organ Procurement and Transplantation Network Web site. Available at: http://www.optn.org. Accessed March 2009.

3. Farrar DJ. Ventricular interactions during mechanical circulatory support. Semin Thorac Cardiovasc Surg. 1994;6:163-8.

4. Farrar DJ, Compton PG, Hershon JJ, Fonger JD, Hill JD. Right heart interaction with the mechanically assisted left heart. World J Surg. 1985;9:89-102.

5. El-Banayosy A, Arusoglu L, Kizner L, Fey O, Minami K, Korfer R. Complications of circulatory assist. Perfusion. 2000;15:327-31

6. Frazier OH, Rose EA, Oz MC, Dembitsky W, McCarthy P, Radovancevic B, et al Multicenter clinical evaluation of the HeartMate vented electric left ventricular assist system in patients awaiting heart transplantation. J Thorac Cardiovasc Surg. 2001;122:1186-95.

7. Goldstein DJ, Seldomridge JA, Chen JM, Catanese KA, DeRosa CM, Weinberg $\mathrm{AD}$, et al. Use of aprotinin in LVAD recipients reduces blood loss, blood use, and perioperative mortality. Ann Thorac Surg. 1995;59:1063-8.

8. Kavarana MN, Pessin-Minsley MS, Urtecho J, Catanese KA, Flannery M, $\mathrm{Oz} \mathrm{MC}$, et al. Right ventricular dysfunction and organ failure in left ventricular assist device recipients: a continuing problem. Ann Thorac Surg. 2002; 73:745-50.

9. Ochiai Y, McCarthy PM, Smedira NG, Banbury MK, Navia JL, Feng J, et al. Predictors of severe right ventricular failure after implantable left ventricular assis device insertion: analysis of 245 patients. Circulation. 2002;106(suppl 1): I198-202.

10. Poirier VL. The HeartMate left ventricular assist system: worldwide clinical results. Eur J Cardiothorac Surg. 1997;11(suppl):S39-44.

11. Farrar DJ, Hill JD, Pennington DG, McBride LR, Holman WL, Kormos RL, et al Preoperative and postoperative comparison of patients with univentricular and biventricular support with the Thoratec ventricular assist device as a bridge to cardiac transplantation. J Thorac Cardiovasc Surg. 1997;113:202-9.

12. Morgan JA, John R, Lee BJ, Oz MC, Naka Y. Is severe right ventricular failure in left ventricular assist device recipients a risk factor for unsuccessful bridging to transplant and post-transplant mortality. Ann Thorac Surg. 2004;77:859-63.

13. Fitzpatrick JR 3rd, Frederick JR, Hiesinger W, Hsu VM, McCormick RC, Kozin ED, et al. Early planned institution of biventricular mechanical circulatory support results in improved outcomes compared with delayed conversion of a left ventricular assist device to a biventricular assist device. J Thorac Cardiovasc Surg. 2009;137:971-7.

14. Tsukui H, Teuteberg JJ, Murali S, McNamara DM, Buchanan JR, Winowich S, et al. Biventricular assist device utilization for patients with morbid congestive heart failure: a justifiable strategy. Circulation. 2005;112(suppl):I65-72.

15. Dang NC, Topkara VK, Mercando M, Kay J, Kruger KH, Aboodi MS, et al. Right heart failure after left ventricular assist device implantation in patients with chronic congestive heart failure. J Heart Lung Transplant. 2006;25:1-6.

16. Matthews JC, Koelling TM, Pagani FD, Aaronson KD. The right ventricular failure risk score a pre-operative tool for assessing the risk of right ventricular failure in left ventricular assist device candidates. J Am Coll Cardiol. 2008;51: 2163-72.

17. Maeder MT, Leet A, Ross A, Esmore D, Kaye DM. Changes in right ventricular function during continuous-low left ventricular assist device support. J Heart Lung Transplant. 2009;28:360-6.

18. Miller LW, Pagani FD, Russell SD, John R, Boyle AJ, Aaronson KD, et al. Use of a continuous-flow device in patients awaiting heart transplantation. N Engl J Med. 2007;357:885-96.

19. Pagani FD, Miller LW, Russell SD, Aaronson KD, John R, Boyle AJ, et al. Extended mechanical circulatory support with a continuous-flow rotary left ventricular assist device. J Am Coll Cardiol. 2009;54:312-21.

20. Kopman EA, Ferguson TB. Interaction of right and left ventricular filling pressures at the termination of cardiopulmonary bypass. Central venous pressure/pulmonary capillary wedge pressure ratio. J Thorac Cardiovasc Surg. 1985;89:706-8.

21. Fukamachi K, McCarthy PM, Smedira NG, Vargo RL, Starling RC, Young JB. Preoperative risk factors for right ventricular failure after implantable left ventricular assist device insertion. Ann Thorac Surg. 1999;68:2181-4. 
22. Moon MR, Bolger AF, DeAnda A, Komeda M, Daughters GT 2nd, Nikolic SD, et al. Septal function during left ventricular unloading. Circulation. 1997;95:1320-7.

23. Kormos RL, Gasior TA, Kawai A, Pham SM, Murali S, Hattler BG, et al. Transplant candidate's clinical status rather than right ventricular function defines need for univentricular versus biventricular support. J Thorac Cardiovasc Surg. 1996; 111:773-83.
24. Potapov EV, Stepanenko A, Dandel M, Kukucka M, Lehmkuhl HB, Weng Y, et al. Tricuspid incompetence and geometry of the right ventricle as predictors of right ventricular function after implantation of a left ventricular assist device. J Heart Lung Transplant. 2008;27:1275-81.

25. Van Meter CH Jr. Right heart failure: best treated by avoidance. Ann Thorac Surg. 2001;71(suppl):S220-2. 